\title{
DISCOVERY
}

\section{Biochemical Conglomeration And Its Relation With Some Character Of Importance In Barnyard Fowls}

\author{
Dr.Devendra Patel \\ Lala Lajpat Rai University Of Veterinary And Animal Sciences India
}

\begin{abstract}
The term 'protein' comes from the Greek word 'Proteins' which means primary and is so well chosen, since proteins the primary recognizable and distinctive expression of genetic info. The structure of proteins change them to act because the catalysts that management the rates of all biological reactions, to function the carriers essential substances at intervals the organisms, to function regulators, of physiological relationship and to function building block units for substances, cellular and organic structures. The incidence of 2 or a lot of discontinuous varieties of super molecule in a very species in such a proportion that rarest of them can not be maintained simply by repeated mutation is termed super molecule conglomeration. The information regarding these biological variations or conglomeration systems has terribly wide ramifications and applications in biological sciences. it's through an experiment tried that each one traits of production, replica and genetic diseases area unit controlled by the organic chemistry activities within the body of the people and these area unit accomplished by the many styles of super molecules like bodily fluid protein, enzyme, endocrine etc.. These completely different proteins show their effects in numerous ways that viz. anabolic, catabolic, activating the substrate etc. that controls the expansion, production and replica of the people.
\end{abstract}

Keywords: Biochemical Diversity, organic chemistry Conglomeration , siderophilin (Tf) variants

\section{Genetic management on organic chemistry Conglomeration :}

it's assumed that one or a lot of all allomorphic combine of genes controls all kinds of organic chemistry conglomeration. it's conjointly tried that many styles of super molecule variations area unit thanks to the various variety of amino acids gift within the super molecule molecules and exert their effects in numerous manner. A genetic code of ester of polymer and ribonucleic acid is liable for cryptography of explicit a specific selected\} aminoalkanoic acid to participate within the formation of a super molecule different amino acids to return in a very particular 


\section{THE AMERICAN JOURNAL OF}

\section{DISCOVERY}

arrangement to make a specific protein that in for good or quickly needed for a specific perform of the body. If the allomorphic combine of genes having an equivalent ester sequences in each the genes, they'll send an equivalent style of codes to the amino acids to return in grips to make the similar style of super molecule that's monomorphic super molecule. however if the allomorphic combine of genes having \{the completely different the various\} codons to different amino acids to return in grips in this explicit sequence of ester within the polymer or ribonucleic acid to make the various super molecule molecules. By this sequence controlled fashion, a special style of polymorphic super molecule is created within the body and exerts their effects in numerous ways that.

\section{Biochemical Diversity :}

Organic chemistry diversity popularly referred to as organic chemistry conglomeration is that the incidence of the varieties attributed to organic chemistry distinction, that area unit beneath genetic management. A population is alleged to exhibit genetic conglomeration once 2 or a lot of distinct transmissible varieties coexisted within the same people. A genetic character is currently to be polymorphic once the rarest composition includes a frequency bigger than onehundredth. Organic chemistry conglomeration includes a wide incidence in nature. sequence controls organic chemistry conglomeration until now disclosed has aggravated abundant discussion with relevance its origin, maintenance and significance of state. it's believed that the balance between the adjective values of various sequence varieties beneath varied environments would be liable for its maintenance.

\section{Objectives to check the organic chemistry Conglomeration :}

i. The ribozymes or multiple molecular varieties of super molecule provides natural integrate the genetic markers that facilitate in verify the changes of genetic variability with a population and which may be used as labels within the study of choice, serving to detection to lift higher people.

ii. Robbers represented the importance of organic chemistry conglomeration within the improvement of chicken. it absolutely was conjointly noted by Rendell (1967) that a number of polymorphic alleles could also be related with economic traits thanks to linkage pleotropic or 


\section{THE AMERICAN JOURNAL OF}

VETERINARY SCIENCES AND WILDLIFE

VOLUME01 ISSUE02

\section{DISCOVERY}

general state. If to date these polymorphic character expressed throughout the first lifetime of a personal so the choice is created at right time while not actual recording of the assembly of the issue and genetic gain per unit of your time is accrued.

iii. The marker therefore developed through organic chemistry studies will encourage be useful in evaluating genetically illness free strain in barnyard fowls and in establishing individuality and to resolve controversial proportion.

\section{Non-immunological super molecule Conglomeration in regard to Economic Traits in barnyard fowls :}

Blood super molecule together with their variants in barnyard fowls is also positively connected with the economic traits in barnyard fowls. From the on the market literature a number of the proteins and their genetic variants having specific roles on the management of economic traits could also be printed as below. however the knowledge cited is unquestionably way for the adequacy

\section{A. hemoglobin $(\mathrm{Hb})$ variants :}

Hemoglobin is that the principle molecule for transport of greenhouse emission in blood. it's a \{conjugated super molecule compound protein protein\} and consists of the protein globin and prosthetic cluster hemoglobin. every molecule consists of 4 polypeptides. in step with Damari (1978), 3 styles of hemoglobin are discovered that area unit controlled by 2 chromosome alleles A1 and A2. Maunder et al. (1989) apparently according that the frequencies of the conventional $\mathrm{Hb}$ sequence in white hat : zero.96, in broiler:1.00, in native fowl:1.00, in guinea fowl:1.00, in quail:0.85, corresponding figures for the conventional mutant alleles were zero.04, 0.00, 0.00, 0.00 and 0.15 .

\section{B. siderophilin (Tf) variants :}




\section{THE AMERICAN JOURNAL OF}

VETERINARY SCIENCES AND WILDLIFE

VOLUME01 ISSUE02

\section{DISCOVERY}

In birds siderophilin is understood to perform as biological process agent in eggs by sterilization the $\mathrm{Fe}++/ \mathrm{Co}++$ quantitative relation. The siderophilin conglomeration in barnyard fowls ( lightweight geographic region stock ) 1st according by Ogden et al. (1962). 3 styles of alleles viz. TfA, TfB and TfC were discovered in chicken by religious belief (1977). On the gel activity separation the homozygous varieties were found to exhibit 2 bands whereas the heterozygous varieties 3-4 bands distinctively.

\section{C. bodily fluid AL calescent enzyme (SAP) variants :}

it's a vital catalyst within the chicken that is princely found in bones, kidney, liver, plasma, internal organ mucose. It functions to assist in absorption of super molecule, super molecule and fat. Tamaki and Tanana (1970) according 2 alleles viz. F and S in respect of SAP locus.

\section{Plasma albumen variants :}

Plasma albumen conglomeration in many brown hat chicken was according by Condone (1962). 2 variants were distinguished and assumed to be detected by dominant alleles at one chromosome locus. every variant is in the course of a minor, quicker or fraction house that varies its quality in step with the most fraction.

\section{E. Egg albumen variants :}

By starch gel activity seven proteins area unit outlined. however genetically four forms area unit found in varied populations, named oval albumen, ovalbumin and protein- II and III. every conglomeration is thanks to the segregation of 2 co-dominant alleles at a separate chromosome locus. Egg albumen conglomeration plays to influence hatchability and viability of embryo.

\section{Conclusion}

Most of the necessary non-immunogenic super molecule has some organic chemistry conglomeration. The economic traits like fertility, hatchability, weight, age at sexual maturity, egg production and egg shell quality area unit a lot of or less genetically related with polymorphs of various proteins. however the correlation between polymorphs of pre-albumin, blood 


\section{THE AMERICAN JOURNAL OF}

VETERINARY SCIENCES AND WILDLIFE

VOLUME01 ISSUE02

\section{DISCOVERY}

corpuscle enzyme, plasma albumen, bodily fluid esterase and also the procreative attribute has not nevertheless found. Hatchability and fertility as suffering from hemoglobin and siderophilin conglomeration area unit to be noted. bodily fluid AL calescent enzyme, siderophilin and hemoglobin conglomeration have an effect on the boy weight and egg production. In chicken variations in one blood type locus area unit related to variations in rejection of skin homo-grafts associated in another with susceptibleness to infection by an vertebrate leucosis malignant neoplastic disease virus.

\section{References}

1. Al-Awsat, S.P.S. (1999): Indian barnyard fowls Review, -24 .

2. Pravakaran, R.,et.al.(2005): Indian Journal of barnyard fowl science, 185-187.

3. Grendel, J. (1997): Animal Breeding Abstract.

4. Damari, C.S.; Singh, H.; Joshi, H.B. and Bats, G.S. (1990): Indian Journal of Animal Science.

5. Washburn, K.W.; Edison, C.S. and Lowe, R.M. (2001):barnyard fowls Science. 